\title{
Association of CYP1B1 L432V polymorphism with urinary cancer susceptibility: a meta-analysis
}

\author{
Weifan Jiang ${ }^{1 *}$, Guang Sun², Jianhua Xiong ${ }^{1}$, Xiaoqing $X^{1}$ and Zimin Shi
}

\begin{abstract}
Background: The Cytochrome P450 1B1 (CYP1B1) is a key P450 enzyme involved in the metabolism of exogenous and endogenous substrates. Previous studies have reported the existence of CYP1B1 L432V missense polymorphism in prostate, bladder and renal cancers. However, the effects of this polymorphism on the risk of these cancers remain conflicting. Therefore, we performed a meta-analysis to assess the association between L432V polymorphism and the susceptibility of urinary cancers.

Methods: We searched the PubMed database without limits on language for studies exploring the relationship of CYP1B1 L432V polymorphism and urinary cancers. Article search was supplemented by screening the references of retrieved studies manually. Odds ratios (OR) and $95 \%$ confidence intervals (95\% Cl) were calculated to evaluate the strength of these associations. Simultaneously, publication bias was estimated by funnel plot and Begg's test with Stata 11 software.
\end{abstract}

Results: We observed a significant association between CYP1B1 L432V polymorphism and urinary cancers. The overall OR (95\% Cl) of CC versus CG was 0.937 (0.881-0.996), the overall OR (95\% Cl) of CC versus CG + GG was 0.942 (0.890-0.997). Furthermore, we identified reduced risk for CC versus other phenotypes in both prostate and overall urinary cancers, when studies were limited to Caucasian or Asian patients.

Conclusions: This meta-analysis suggests that the CYP1B1 L432V polymorphism is associated with urinary cancer risk.

Virtual Slides: The virtual slide(s) for this article can be found here: http://www.diagnosticpathology.diagnomx.eu/ vs/3108829721231527

Keywords: CYP1B1, Polymorphism, Urinary cancer, Susceptibility, Meta-analysis

\section{Background}

Prostate cancer, urothelial carcinoma and renal cancer are common cancer types and major cause of cancerrelated death worldwide [1,2]. Smoking, diet and environmental factors have been reported to contribute to the carcinogenesis of these malignancies [3,4]. However, the fact that a small fraction of people exposed to these carcinogens eventually develop urinary cancers suggests that individual genetic predisposition factors may contribute to carcinogenesis.

Cytochrome P450 1B1 (CYP1B1) is a member of the CYP1 gene family and one of the major enzymes involved

\footnotetext{
*Correspondence: jiangweifan163@126.com

'Department of Urology, the Second Affiliated Hospital, Nanchang University, Nanchang, China

Full list of author information is available at the end of the article
}

in the hydroxylation of estrogens, involved in the oxidative activation and deactivation of xenobiotics [5-7]. Several polymorphisms in the CYP1B1 gene have been reported, including 4326C/G (L432V, rs1056836) in exon 3, which encodes the heme-binding domain, have been associated with enhanced catalytic activity when compared to the wild-type allele [8-10].

Polymorphisms in XPC and MHTFR gene have been reported to be associated with overall urinary cancer risk $[11,12]$, suggesting that urinary cancers share common mechanisms in the process of DNA repair and carcinogen metabolism. Several case-control studies were performed to identify the association of $C Y P 1 B 1$ polymorphisms with prostate, bladder and renal cancer risk. However, small sample sizes and limited populations in study design have often yielded inclusive results among the studies [13-29]. 
The inconsistent conclusions may have resulted from difference ethnic backgrounds and relatively small sample sizes. To validate the potential association between the CYP1B1 Leu432Val polymorphism and urinary cancer risk, we conducted a meta-analysis of data reported in 17 studies including 7,944 cases and 7,389 controls.

\section{Methods}

\section{Publication search}

Medline, PubMed, Embase and Web of Science were searched for all relevant articles with the following terms: "Cytochrome P450 1B1" or "CYP1B1", "polymorphism" or "variant", "case-control", "risk", "association", "prostate cancer", "bladder cancer" and "renal cancer" (last search was updated on Feb 10, 2014). References of the retrieved articles on this topic were also manually screened for additional relevant eligible studies.

\section{Selection criteria}

We defined inclusion criteria as follows: written in English; case-control design; sufficient information for estimating odds ratio (OR) and their 95\% confidence interval (CI); observed genotype frequencies in the controls in agreement with Hardy-Weinberg equilibrium (HWE). Abstracts and unpublished reports were not considered. Investigations in subjects with family history or cancer-prone disposition were also excluded. Meanwhile, if studies had overlapping subjects, we selected the most recent study that included the largest number of individuals in the publications. This study was approved by the ethics committee of the Second Affiliated Hospital of Nanchang University.

\section{Data extraction}

Two investigators independently extracted the following information from each study: the first author, year of publication, country of origin, ethnicity, source of controls (population-based, hospital-based and mixed controls), genotyping method, number of genotyped cases and controls, number of genotypes for three CYP1B1 polymorphisms in cases and controls, and main findings.

\section{Statistical methods}

Hardy-Weinberg equilibrium (HWE) was evaluated for each study, using the goodness-of-fit chi-square test. $P<0.05$ was considered representative of departure from HWE. Crude OR with $95 \%$ CI was used to assess the strength of association between the three CYP1B1 L432V polymorphism and urinary cancer risk. Then, we calculated the pooled ORs and $95 \%$ CIs. Heterogeneity assumption was checked by the chi-square-based Q-test. A $P$ value greater than 0.10 for the Q-test indicates a lack of heterogeneity among studies, so the pooled OR estimate of the each study was calculated by the fixed-effects model (the Mantel-Haenszel method), the random-effects model (the Der-Simonian and Laird method) was used otherwise $[30,31]$. To assess the effects of individual studies on the overall risk of cancer, sensitivity analysis was performed by excluding each study at a time individually and recalculating the ORs and 95\% CIs. We also used the inverted funnel plot and the Egger's test to examine the potential influence of publication bias (linear regression analysis). The significance of the intercept was determined by the t-test suggested by Egger $(P<0.05$ was considered representative of statistically significant publication bias) [32]. All statistical tests were two-sided, and a P-value of $<0.05$ was considered statistically significant. Statistical tests were performed with STATA version 11.0 (Stata Corporation, College Station, TX) or SAS software (version 9.1; SAS Institute, Cary, NC).

\section{Results and discussion}

\section{Study characteristics}

We identified a total of 71 relevant publications after initial screening. Among these, 26 publications had met the inclusion criteria and were subjected to further examination. We excluded 4 publications because they did not present detailed genotyping information. We also excluded 5 publications because they did not include L432V polymorphism. Our final data consisted of 10 publications with a total of 5949 cases and 5388 controls for prostate cancer, 5 publications with 1658 cases and 1593 controls for bladder cancer, 2 publications with 337 cases and 408 controls for renal cancer (Figure 1). Of these, there were 10 hospital-based studies and 7 population-based studies. Characteristics of included studies are summarized in Table 1.

\section{Quantitative synthesis}

Table 2 lists the main results of this meta-analysis. Overall, significant associations were found between CYP1B1 L432V polymorphism and urinary cancer risk when all

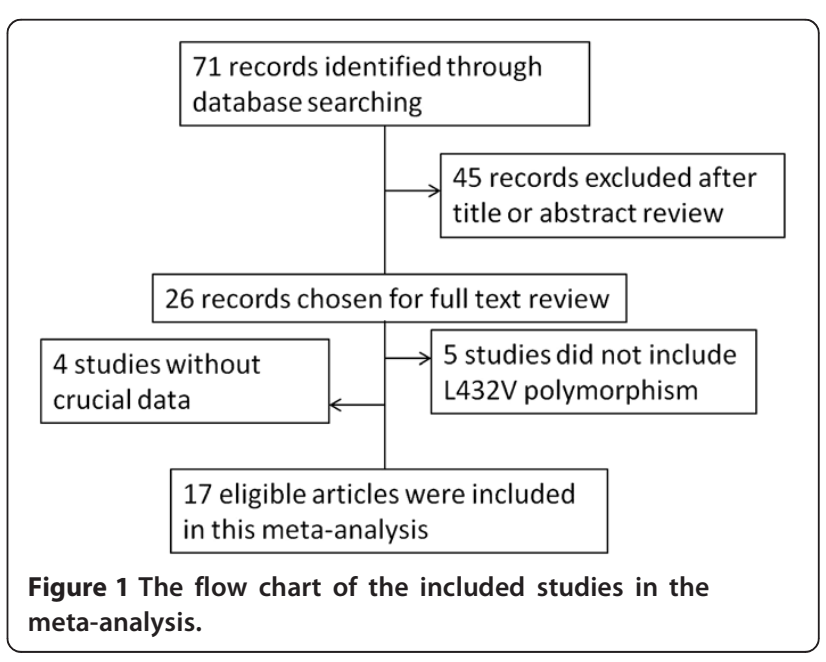


Table 1 Characteristics of studies included in the meta-analysis for an association between CYP1B1 L432V SNP and risk of urinary cancer

\begin{tabular}{|c|c|c|c|c|c|c|c|c|}
\hline First author, year & Country & Ethnicity & $\begin{array}{l}\text { Source of } \\
\text { control }\end{array}$ & $\begin{array}{l}\text { Cases/ } \\
\text { controls }\end{array}$ & $\begin{array}{l}\text { MAF of } \\
\text { controls }\end{array}$ & Power $^{a}$ & $\begin{array}{l}\text { Source of } \\
\text { DNA }\end{array}$ & $\begin{array}{l}\text { Genotyping } \\
\text { methods }\end{array}$ \\
\hline \multicolumn{9}{|l|}{ Prostate cancer } \\
\hline Holt, 2013 & USA & Caucasian & PB & $1256 / 1235$ & 0.41 & 1 & blood & SNPlex \\
\hline Catsburg C, 2012 & USA & Caucasian & PB & $1433 / 760$ & 0.47 & 1 & blood & Taqman \\
\hline Beuten J, 2008 & USA & Caucasian & PB & $649 / 738$ & 0.39 & 1 & blood & Taqman \\
\hline Berndt, 2007 & USA & Mixed & PB & $486 / 611$ & 0.47 & 1 & blood & TaqMan \\
\hline Cussenot O, 2007 & France & Caucasian & $\mathrm{HB}$ & $1053 / 837$ & 0.39 & 1 & blood & TaqMan \\
\hline Sobti RC, 2006 & India & Asian & PB & $100 / 100$ & 0.18 & 0.415 & blood & PCR-RFLP \\
\hline Cicek MS, 2005 & USA & Mixed & $H B$ & $439 / 479$ & 0.47 & 1 & blood & PCR-RFLP \\
\hline Fukatsu, 2004 & Japan & Asian & $\mathrm{HB}$ & $136 / 255$ & 0.29 & 0.947 & blood & PCR-RFLP \\
\hline Chang BL, 2003 & USA & Mixed & $\mathrm{HB}$ & $310 / 182$ & 0.44 & 0.807 & ND & Sequencing \\
\hline Tanaka Y, 2002 & Japan & Asian & PB & $117 / 200$ & 0.18 & 0.857 & ND & AS-PCR \\
\hline \multicolumn{9}{|l|}{ Bladder cancer } \\
\hline Berber U, 2013 & Turkey & Asian & PB & $114 / 114$ & 0.27 & 0.499 & tissue & AS-PCR \\
\hline Salinas-Sánchez AS, 2012 & Spain & Caucasian & $\mathrm{HB}$ & $208 / 208$ & 0.39 & 0.875 & blood & Sequencing \\
\hline Fontana L, 2009 & France & Caucasian & $\mathrm{HB}$ & $51 / 45$ & 0.58 & 0.104 & blood & TaqMan \\
\hline Figueroa J, 2008 & Spain & Caucasian & $\mathrm{HB}$ & $1084 / 1012$ & 0.42 & 1 & blood/buccal & TaqMan \\
\hline Hung RJ, 2004 & Italy & Caucasian & $H B$ & $201 / 214$ & 0.59 & 0.888 & ND & PCR-RFLP \\
\hline \multicolumn{9}{|l|}{ Renal cancer } \\
\hline Salinas-Sánchez AS, 2012 & Spain & Caucasian & $\mathrm{HB}$ & $126 / 208$ & 0.39 & 0.875 & blood & Sequencing \\
\hline Sasaki M, 2005 & USA & Asian & $H B$ & $211 / 200$ & 0.18 & 0.857 & tissue & AS-PCR \\
\hline
\end{tabular}

Abbreviations: SNP Single nucleotide polymorphism, $H B$ Hospital based, $P B$ Population based, RFLP Restriction fragment length polymorphisms, $A S-P C R$ Allele

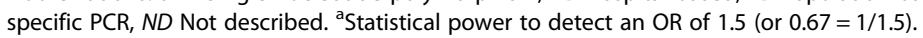

Table 2 Meta-analysis of the associations between CYP1B1 L432V polymorphism and urinary cancer risk

\begin{tabular}{|c|c|c|c|c|c|c|c|c|c|c|}
\hline \multirow[t]{2}{*}{ Cancer } & \multirow[t]{2}{*}{ Number of studies } & \multirow[t]{2}{*}{ Cases/controls } & \multirow[t]{2}{*}{ Comparison } & \multicolumn{3}{|c|}{ Test of association } & \multicolumn{3}{|c|}{ Test of heterogeneity } & \multirow{2}{*}{$\frac{\text { Publication bias }}{P \text { Value (Begg's }}$} \\
\hline & & & & $\overline{\mathrm{OR}}$ & $95 \% \mathrm{Cl}$ & $P$ Value & $\bar{Q}$ & $P$ Value & $\mathrm{I}^{2}(\%)$ & \\
\hline \multirow[t]{4}{*}{ Prostate } & 10 & $5949 / 5388$ & CC vs GG & 0.942 & $0.868-1.022$ & 0.151 & 20.23 & 0.017 & 55.5 & 0.917 \\
\hline & & & CC vs CG & 0.947 & $0.881-1.018$ & 0.137 & 23.13 & 0.006 & 61.1 & 0.212 \\
\hline & & & $C C$ vs $C G+G G$ & 0.952 & $0.895-1.013$ & 0.120 & 20.00 & 0.018 & 55.0 & 0.671 \\
\hline & & & C vs $G$ & 0.963 & $0.920-1.008$ & 0.108 & 24.36 & 0.004 & 63.0 & 0.723 \\
\hline \multirow[t]{4}{*}{ Bladder } & 5 & $1658 / 1593$ & CC vs GG & 1.061 & $0.962-1.171$ & 0.234 & 2.23 & 1 & 0.0 & 0.035 \\
\hline & & & CC vs CG & 1.000 & $0.926-1.079$ & 0.991 & 7.20 & 0.126 & 44.4 & 0.317 \\
\hline & & & $C C$ vs $C G+G G$ & 1.016 & $0.947-1.090$ & 0.661 & 6.25 & 0.181 & 36.0 & 0.156 \\
\hline & & & C vs $G$ & 1.026 & $0.977-1.077$ & 0.312 & 3.75 & 0 & 0.0 & 0.060 \\
\hline \multirow[t]{4}{*}{ Renal } & 2 & $337 / 408$ & CC vs GG & 0.740 & $0.593-0.922$ & 0.007 & 0.73 & 0.394 & 0 & - \\
\hline & & & CC vs CG & 0.816 & $0.686-0.969$ & 0.021 & 1.34 & 0.248 & 25.2 & - \\
\hline & & & $C C$ vs $C G+G G$ & 0.787 & $0.673-0.922$ & 0.003 & 1.35 & 0.245 & 26.0 & - \\
\hline & & & C vs G & 0.818 & $0.729-0.917$ & 0.001 & 1.82 & 0.178 & 45 & - \\
\hline \multirow[t]{4}{*}{ Overall } & 17 & 7944/7389 & CC vs GG & 0.941 & $0.876-1.012$ & 0.103 & 35.2 & 0.004 & 54.6 & 0.607 \\
\hline & & & CC vs CG & 0.937 & $0.881-0.996$ & 0.037 & 37.29 & 0.002 & 57.1 & 0.076 \\
\hline & & & $C C$ vs $C G+G G$ & 0.942 & $0.890-0.997$ & 0.038 & 37.97 & 0.002 & 57.9 & 0.199 \\
\hline & & & C vs G & 0.957 & $0.917-0.998$ & 0.039 & 46.07 & 0 & 65.3 & 0.302 \\
\hline
\end{tabular}


a

Study

ID
$\%$

$\mathrm{RR}(95 \% \mathrm{Cl}) \quad$ Weight

$0.90(0.82,0.98)$

10.06

Holt SK (2013)

Catsburg C (2012)

Beuten J (2008)

Berndt SI (2007)

Cussenot $O(2007)$

Sobti RC (2006)

Cicek MS (2005)

Fukatsu (2004)

Chang BL (2003)

Tanaka Y (2002)

Berber U (2013)

Salinas-Sanchez AS (2012)

Fontana L (2009)

Figueroa J (2008)

Hung RJ (2004)

Salinas-Sanchez AS (2012)

Sasaki M (2005)

Overall (l-squared $=57.1 \%, p=0.002$ )

NOTE: Weights are from random effects analysis

$$
3
$$

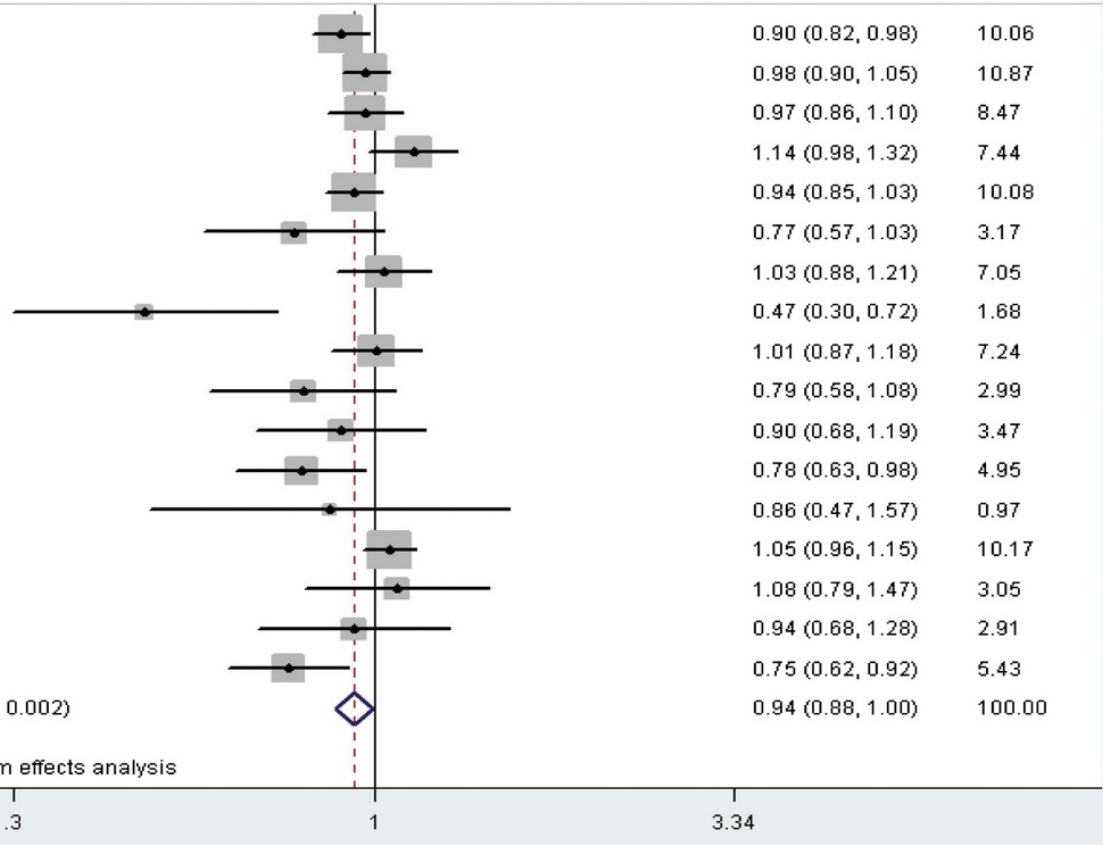

b

Study

ID

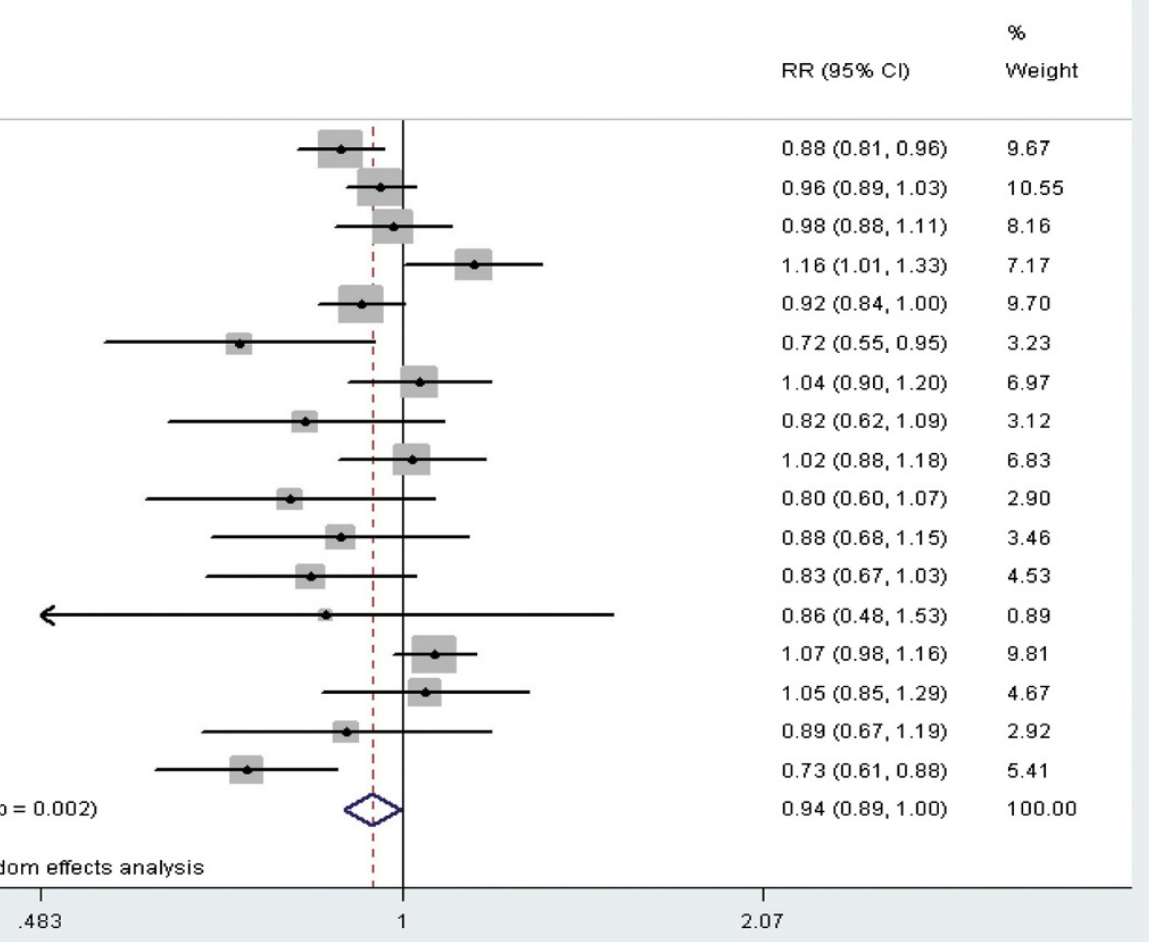

Figure 2 Forest plot (Random effects model) describing the association of the CYP1B1 L432V polymorphism with risk of urinary cancers. The CC phenotype was associated with a modestly decreased risk of urinary cancers (a, CC vS CG; b, CC vs CG + GG). 
studies pooled into the meta-analysis (CC vs CG: $\mathrm{OR}=0.937,95 \% \mathrm{CI}=0.881-0.996 ; \mathrm{CC}$ vs $\mathrm{CG}+\mathrm{GG}$ : $\mathrm{OR}=0.942,95 \% \mathrm{CI}=0.890-0.997 ; \mathrm{C}$ vs $\mathrm{G}: \mathrm{OR}=0.957$, 95\% CI $=0.917-0.998$ ) (Figure 2). In the subgroup analysis, L432V polymorphism was significantly associated with prostate cancer or overall urinary cancer risk when population was defined as only Caucasians or Asians (Additional file 1: Table S1). Nevertheless, when studies were restricted to population-based or hospital-based studies, none of these comparisons showed significant differences. The FPRP values for significant findings at different prior probability levels were also calculated. For a prior probability of 0.1 , assuming that the OR for specific genotype was $0.67 / 1.50$ (protection/risk), the FPRP values were $0.786,0.79$ and 0.794 for an association of overall CC vs CG, CC vs CG + GG and C vs G genotypes with an increased lung cancer risk.

\section{Heterogeneity and sensitivity analyses}

Heterogeneities were observed among studies for the association between the CYP1B1 L432V polymorphism and urinary cancer risk (CC vs GG, CC vs $\mathrm{CG}, \mathrm{CC}$ vs $\mathrm{CG}+\mathrm{GG}, \mathrm{C}$ vs $\mathrm{G}$ for prostate cancer; $\mathrm{C}$ vs $\mathrm{G}$ for bladder cancer; $C C$ vs $G G, C C$ vs $C G, C C$ vs $C G+G G, C$ vs $G$ for overall urinary cancers). Therefore, we used the random-effects model that generated wider CIs. For the other groups of comparisons, no heterogeneity was found among studies and the fixed-effects model was performed (Table 2, Additional file 1: Table S1). The leave-one-out sensitivity analysis indicated that no single study changed the pooled ORs qualitatively (data not shown).

\section{Publication bias}

The shapes of the funnel plots seemed symmetrical, and Egger's test suggested that publication bias was only found in the CC vs GG group of bladder cancer (Table 2, Additional file 1: Table S1).

In this meta-analysis, we tested the association between L432V polymorphism in the CYP1B1 gene and urinary cancer risk by comparing the allele frequencies from 17 published studies. We observed a significant association of L432V polymorphism with overall urinary cancer risk, as well as in the subgroups defined as Caucasian or Asian populations. Urinary system tumorigenesis is a complex event, in which different carcinogenic chemicals are involved. Prostate is a hormone-responsive organ in which androgens are believed to stimulate growth and secretory functions. Evidences have been shown that CYP1B1 protein is highly expressed in prostate cancer tissues, while not in normal prostate tissues [33]. It has been reported that different allelic variants of CYP1B1 have different catalytic activities and specificities to procarcinogens, thus partly explains molecular mechanism of CYP1B1 in carcinogenesis [34]. Except for prostate cancer, case-control studies have shown inconsistent associations between CYP1B1 L432V polymorphism and bladder cancer and renal cancer risk $[24,28,29]$. However, exact mechanisms of how CYP1B1 polymorphism contributes to urinary cancer susceptibility requires further illustration.

Some limitations of this meta-analysis should be discussed. First, the total number of included studies of bladder cancer and renal cancer was relatively small. Second, our results were based on unadjusted estimates, while a more precise analysis is needed if individual data were available, which would allow for the adjustment by other factors such as age, smoking status, drinking status. Finally, unpublished data may have not been included in the current analysis, potentially causing a bias in the results.

\section{Conclusions}

In conclusion, this meta-analysis suggests that the CYP1B1 L432V polymorphism is associated with urinary cancer development, especially in specified Caucasian and Asian populations. However, studies with larger number of samples from homogeneous urinary cancer patients are needed. Further biological investigations may eventually lead to better understanding of the association between the CYP1B1 polymorphism and urinary cancer risk.

\section{Additional file}

Additional file 1: Table S1. Subgroup analysis of association between CYP1B1 L432V polymorphism and urinary cancer risk.

Competing interests

The authors declare that they have no competing interests.

\section{Authors' contributions}

WF J, G S and JH X conceived and performed statistics, WF J, XQ X and ZM S extracted data and wrote the manuscript, G S and ZM S revised the manuscript. All authors read and approved the final manuscript.

\section{Acknowledgements}

This work was supported by Scientific Program of the Department of Education, JiangXi Province, China (GJJ13047).

\section{Author details}

'Department of Urology, the Second Affiliated Hospital, Nanchang University, Nanchang, China. ${ }^{2}$ Department of Urology, The Second Hospital of Tianjin Medical University, Tianjin Institute of Urology, Tianjin, China.

Received: 5 March 2014 Accepted: 21 May 2014

Published: 9 June 2014

\section{References}

1. Jemal A, Bray F, Center MM, Ferlay J, Ward E, Forman D: Global cancer statistics. CA Cancer J Clin 2011, 61:69-90.

2. Siegel R, Ma J, Zou Z, Jemal A: Cancer statistics, 2014. CA Cancer J Clin 2014, 64:9-29.

3. Garcia-Closas M, Rothman N, Figueroa JD, Prokunina-Olsson L, Han SS, Baris D, Jacobs EJ, Malats N, De Vivo I, Albanes D, Purdue MP, Sharma S, Fu YP, Kogevinas M, Wang Z, Tang W, Tardón A, Serra C, Carrato A, García-Closas R, 
Lloreta J, Johnson A, Schwenn M, Karagas MR, Schned A, Andriole G Jr, Grubb R 3rd, Black A, Gapstur SM, Thun M, et al: Common genetic polymorphisms modify the effect of smoking on absolute risk of bladder cancer. Cancer Res 2013, 73:2211-2220.

4. Joshi AD, Corral R, Catsburg C, Lewinger JP, Koo J, John EM, Ingles SA, Stern MC: Red meat and poultry, cooking practices, genetic susceptibility and risk of prostate cancer: results from a multiethnic case-control study. Carcinogenesis 2012, 33:2108-2118.

5. Agundez JA: Cytochrome P450 gene polymorphism and cancer. Curr Drug Metab 2004, 5:211-224.

6. Hayes CL, Spink DC, Spink BC, Cao JQ, Walker NJ, Sutter TR: 17 betaestradiol hydroxylation catalyzed by human cytochrome P450 1B1. Proc Natl Acad Sci U S A 1996, 93:9776-9781.

7. Sutter CH, Qian Z, Hong YP, Mammen JS, Strickland PT, Sutter TR: Genotyping human cytochrome: P450 1B1 variants. Methods Enzymol 2002, 357:53-58.

8. Hanna IH, Dawling S, Roodi N, Guengerich FP, Parl FF: Cytochrome P450 1B1 (CYP1B1) pharmacogenetics: association of polymorphisms with functional differences in estrogen hydroxylation activity. Cancer Res 2000, 60:3440-3444

9. Li DN, Seidel A, Pritchard MP, Wolf CR, Friedberg T: Polymorphisms in P450 CYP1B1 affect the conversion of estradiol to the potentially carcinogenic metabolite 4-hydroxyestradiol. Pharmacogenetics 2000, 10:343-353.

10. Shimada T, Watanabe J, Kawajiri K, Sutter TR, Guengerich FP, Gillam EM, Inoue K: Catalytic properties of polymorphic human cytochrome P450 $1 B 1$ variants. Carcinogenesis 1999, 20:1607-1613.

11. Dou K, Xu Q, Han X: The association between XPC Lys939GIn gene polymorphism and urinary bladder cancer susceptibility: a systematic review and meta-analysis. Diagn Pathol 2013, 8:112.

12. $\mathrm{Xu} \mathrm{W}$, Zhang $\mathrm{H}$, Wang $\mathrm{F}$, Wang $\mathrm{H}$ : Quantitative assessment of the association between MHTFR C677T (rs1801133, Ala222Val) polymorphism and susceptibility to bladder cancer. Diagn Pathol 2013, 8:95.

13. Holt SK, Kwon EM, Fu R, Kolb S, Feng Z, Ostrander EA, Stanford JL: Association of variants in estrogen-related pathway genes with prostate cancer risk. Prostate 2013, 73:1-10.

14. Catsburg C, Joshi AD, Corral R, Lewinger JP, Koo J, John EM, Ingles SA, Stern MC: Polymorphisms in carcinogen metabolism enzymes, fish intake, and risk of prostate cancer. Carcinogenesis 2012, 33:1352-1359.

15. Beuten J, Gelfond JA, Byrne JJ, Balic I, Crandall AC, Johnson-Pais TL, Thompson IM, Price DK, Leach RJ: CYP1B1 variants are associated with prostate cancer in non-Hispanic and Hispanic Caucasians. Carcinogenesis 2008, 29:1751-1757.

16. Berndt SI, Chatterjee N, Huang WY, Chanock SJ, Welch R, Crawford ED, Hayes RB: Variant in sex hormone-binding globulin gene and the risk of prostate cancer. Cancer Epidemiol Biomarkers Prev 2007, 16:165-168.

17. Cussenot O, Azzouzi AR, Nicolaiew N, Fromont G, Mangin P, Cormier L, Fournier G, Valeri A, Larre S, Thibault F, Giordanella JP, Pouchard M, Zheng $Y$, Hamdy FC, Cox A, Cancel-Tassin G: Combination of polymorphisms from genes related to estrogen metabolism and risk of prostate cancers: the hidden face of estrogens. J Clin Oncol 2007, 25:3596-3602.

18. Sobti RC, Onsory K, Al-Badran Al, Kaur P, Watanabe M, Krishan A, Mohan H: CYP17, SRD5A2, CYP1B1, and CYP2D6 gene polymorphisms with prostate cancer risk in North Indian population. DNA Cell Biol 2006, 25:287-294.

19. Cicek MS, Liu X, Casey G, Witte JS: Role of androgen metabolism genes CYP1B1, PSA/KLK3, and CYP11alpha in prostate cancer risk and aggressiveness. Cancer Epidemiol Biomarkers Prev 2005, 14:2173-2177.

20. Fukatsu T, Hirokawa Y, Araki T, Hioki T, Murata T, Suzuki H, Ichikawa T, Tsukino H, Qiu D, Katoh T, Sugimura Y, Yatani R, Shiraishi T, Watanabe M: Genetic polymorphisms of hormone-related genes and prostate cancer risk in the Japanese population. Anticancer Res 2004, 24:2431-2437.

21. Chang BL, Zheng SL, Isaacs SD, Turner A, Hawkins GA, Wiley KE, Bleecker ER, Walsh PC, Meyers DA, Isaacs WB, Xu J: Polymorphisms in the CYP1B1 gene are associated with increased risk of prostate cancer. Br J Cancer 2003 89:1524-1529

22. Tanaka $Y$, Sasaki M, Kaneuchi M, Shiina H, Igawa M, Dahiya R: Polymorphisms of the CYP1B1 gene have higher risk for prostate cancer. Biochem Biophys Res Commun 2002, 296:820-826.

23. Berber U, Yilmaz I, Yilmaz O, Haholu A, Kucukodaci Z, Ates F, Demirel D: CYP1A1 (Ile462Val), CYP1B1 (Ala119Ser and Val432Leu), GSTM1 (null), and GST1 (null) polymorphisms and bladder cancer risk in a Turkish population. Asian Pac J Cancer Prev 2013, 14:3925-3929.

24. Salinas-Sanchez AS, Donate-Moreno MJ, Lopez-Garrido MP, Gimenez-Bachs JM, Escribano J: Role of CYP1B1 gene polymorphisms in bladder cancer susceptibility. J Urol 2012, 187:700-706

25. Fontana L, Delort L, Joumard L, Rabiau N, Bosviel R, Satih S, Guy L, Boiteux JP, Bignon YJ, Chamoux A, Bernard-Gallon DJ: Genetic polymorphisms in CYP1A1, CYP1B1, COMT, GSTP1 and NAT2 genes and association with bladder cancer risk in a French cohort. Anticancer Res 2009, 29:1631-1635.

26. Figueroa JD, Malats N, Garcia-Closas M, Real FX, Silverman D, Kogevinas M, Chanock S, Welch R, Dosemeci M, Lan Q, Tardón A, Serra C, Carrato A García-Closas R, Castaño-Vinyals G, Rothman N: Bladder cancer risk and genetic variation in AKR1C3 and other metabolizing genes. Carcinogenesis 2008, 29:1955-1962.

27. Hung RJ, Boffetta P, Brennan P, Malaveille C, Hautefeuille A, Donato F, Gelatti U, Spaliviero M, Placidi D, Carta A, Scotto di Carlo A, Porru S: GST, NAT, SULT1A1, CYP1B1 genetic polymorphisms, interactions with environmental exposures and bladder cancer risk in a high-risk population. Int J Cancer 2004, 110:598-604.

28. Salinas-Sanchez AS, Sanchez-Sanchez F, Donate-Moreno MJ, Rubio-delCampo A, Serrano-Oviedo L, Gimenez-Bachs JM, Martinez-Sanchiz C, Segura-Martin M, Escribano J: GSTT1, GSTM1, and CYP1B1 gene polymorphisms and susceptibility to sporadic renal cell cancer. Urol Oncol 2012, 30:864-870

29. Sasaki M, Tanaka Y, Okino ST, Nomoto M, Yonezawa S, Nakagawa M, Fujimoto S, Sakuragi N, Dahiya R: Polymorphisms of the CYP1B1 gene as risk factors for human renal cell cancer. Clin Cancer Res 2004, 10:2015-2019.

30. DerSimonian R, Laird N: Meta-analysis in clinical trials. Control Clin Trials 1986, 7:177-188.

31. Mantel N, Haenszel W: Statistical aspects of the analysis of data from retrospective studies of disease. J Natl Cancer Inst 1959, 22:719-748.

32. Egger M, Davey Smith G, Schneider M, Minder C: Bias in meta-analysis detected by a simple, graphical test. BMJ 1997, 315:629-634.

33. Carnell DM, Smith RE, Daley FM, Barber PR, Hoskin PJ, Wilson GD, Murray GI, Everett SA: Target validation of cytochrome P450 CYP1B1 in prostate carcinoma with protein expression in associated hyperplastic and premalignant tissue. Int J Radiat Oncol Biol Phys 2004, 58:500-509.

34. Shimada T, Watanabe J, Inoue K, Guengerich FP, Gillam EM: Specificity of 17beta-oestradiol and benzo[a]pyrene oxidation by polymorphic human cytochrome P4501B1 variants substituted at residues 48, 119 and 432. Xenobiotica 2001, 31:163-176.

doi:10.1186/1746-1596-9-113

Cite this article as: Jiang et al:: Association of CYP1B1 L432V polymorphism with urinary cancer susceptibility: a meta-analysis. Diagnostic Pathology 2014 9:113

\section{Submit your next manuscript to BioMed Central and take full advantage of:}

- Convenient online submission

- Thorough peer review

- No space constraints or color figure charges

- Immediate publication on acceptance

- Inclusion in PubMed, CAS, Scopus and Google Scholar

- Research which is freely available for redistribution 